\title{
Early Prediction of Myocardial Viability after Acute Myocardial Infarction by Two-Dimensional Speckle Tracking Imaging \\ ${ }^{1}$ O.S.Arafa , ${ }^{1}$ M.M.Ali , ${ }^{1}$ N.A.El-Meligy,${ }^{2}$ A.A.kata and ${ }^{1}$ M.A.Aboutaha \\ ${ }^{1}$ Cardiovascular Dept., Faculty of Medicine, Benha Univ., Benha, Egypt \\ ${ }^{2}$ Cardiovascular Dept., National Heart Institute, Egypt \\ E-Mail:dr.mohamedtaha83@gmail.com
}

\begin{abstract}
Distinguishing the transmural degree of myocardial rot and the level of myocardial suitability in intense myocardial localized necrosis (AMI) is significant clinically. was to survey myocardial suitability utilizing two-dimensional dot following imaging (2D-STI) in patients with AMI. 2D-STI was performed inside three days of medical clinic affirmation and a half year after essential percutaneous coronary intercession (PCI) in 50 patients with AMI, who had a left front plummeting coronary conduit (LAD) offender sore. What's more, 25 patients who had negligible stenotic injuries $(<$ $30 \%$ stenosis) on coronary angiography were additionally remembered for the benchmark group. At a half year dobutamine echocardiography was performed for reasonability evaluation in seven sections of the LAD region. As indicated by the recuperation of divider movement variation from the norm, sections were named feasible or non-reasonable. An aggregate of 288 portions were feasible, and 62 were nonviable. There is factual noteworthy distinction between the feasible and nonviable sections in the pinnacle systolic strain and the pinnacle systolic strain rate estimated inside three days from intense myocardial dead tissue. AUC for top systolic strain $(0.957$, p. <0.001), 95\%C.I. $(0.937-0.976)$ demonstrated that a cut off degree of $<-9$ had affectability of 86.11 and particularity 87.1 for expectation of practical myocardium. AUC for top systolic strain rate (0.87, p. <0.001), 95\%C.I. (0.809 $-0.931)$ demonstrated that a cut off degree of <-0.7 had affectability of 91.6 and explicitness 74.19 for forecast of practical myocardium.peak longitudinal Strain and strain rate estimations are attainable, reasonable, quantitative, and quick strategies that can foresee myocardial feasibility with high affectability and particularity.
\end{abstract}

\section{Introduction}

Essential PCI is characterized as percutaneous catheter intercession in the setting of STEMI, without past fibrinolysis. It has supplanted fibrinolysis as the favored reperfusion system in patients with STEMI, if it very well may be acted in an opportune way in high-volume PCI focuses with experienced administrators and 24-hour, 7-day catheterization research center activation [1]. Assessment of the suitable myocardium structures is a significant reason for revascularization in patients with intense myocardial localized necrosis (AMI) [2]. This can be evaluated utilizing Dobutamine Echocardiography, F18-fluorodeoxyglucose (FDG) positron emanation tomography (PET), perfusion checks, 64-cut figured tomography (CT), and difference improved attractive reverberation imaging (MRI). Albeit a wide range of imaging modalities have been utilized, these methodologies are frequently constrained by their accessibility, cost, specialized trouble, abstract character, or a mix of these factors [3]. Echocardiography, then again, is all the more effectively accessible and achievable procedure in the intense setting. The utilization of strain (misshapening) by Doppler evaluates territorial myocardial twisting, and can show anomalous myocardial capacity because of ischemia. A few examiners recommended that strain by means of tissue Doppler pictures (TVI) could fill in as a marker of practicality. In spite of the fact that
TVI and Doppler strain estimations have been utilized most generally in this clinical setting, they are restricted by the point reliance in Doppler [4]. To take out the issue of edge reliance, a technique to quantify strain dependent on two-dimensional spot following imaging (2D-STI) has been created, which gives quantitative and edge free estimations for evaluating the myocardial strain [5].

\section{2. methods}

\subsection{Study population}

This is a prospective observational study including 50 patients with first ST-segment elevation myocardial infarction (STEMI) in the anterior wall planned for primary PCI in National Heart Institute, in addition, there is 25 patients with normal coronary angiography as a control group.

\subsubsection{Inclusion criteria}

Patients are going to be included in this study if they present within 12 hours from the onset of symptoms (characteristic chest pain lasting for at least 30 minutes, not responsive to nitrates, with electrocardiographic STsegment elevation of at least $0.2 \mathrm{mV}$ in two or more contiguous leads, or new left bundlebranch block).

\subsubsection{Exclusion criteria}

Moderate to severe valvular heart disease, Significant systemic disease, Significant arrhythmia, Patients who received 
percutaneous coronary intervention (PCI) after $12 \mathrm{~h}$ of symptom onset and Patients who received thrombolytic therapy instead of PCI.

All the patients are also will be subjected to all of the following:

- Full history taking.

- Full clinical examination.

- ECG at presentation.

- Primary PCI will be performed by a 24hours on-call interventional team, according to standard clinical practice.

\subsection{Echocardiography}

Echocardiographic assessment performed inside three days of clinic confirmation, and a half year after essential percutaneous coronary mediation (PCI) in every one of the 50 patients and the benchmark groups. Utilizing X5-1 transducer, PHILIPS EPIQ 7C machine with 2DSTI of the 7 fragments of LAD region ( mid and apical front divider, apical substandard divider, mid and apical sidelong divider, mid and apical septum)this required apical 2, 3 and 4 chamber sees, The endocardial fringe was followed in an end-systolic edge. The product chose six equidistant tissue-following locales of enthusiasm for the myocardium consequently, and the external fringe was balanced around to the epicardial outskirt. at that point pictures were moved to ECHOPAC for disconnected examination, At a half year Dobutamine Echocardiography will be performed for feasibility evaluation in seven sections of the $\mathrm{LAD}$ region. As per the recuperation of divider movement variation from the norm, fragments of the LAD region will be named suitable or nonreasonable. The recuperation of the local divider movement variation from the norm was characterized as an improvement in the territorial divider movement from akinesia or dyskinesia to typical or gentle hypokinesia. A practical section was characterized as recuperation of the provincial divider movement variation from the norm in echocardiography or dobutamine echocardiography a half year after PCI. A nonpractical portion was characterized as no recuperation of the territorial divider movement anomaly in either echocardiography or dobutamine echocardiography a half year after PCI.

\subsection{Statistics}

Statistical analyses were carried out using the SPSS Statistics for Windows ver. 17.0 software package, A two-sided $\mathrm{P}<0.05$ was considered significant. Continuous variables, presented as means $\pm \mathrm{SD}$, were compared using the independent t-test or Mann-Whitney $\mathrm{U}$ test. Categorical variables, presented as frequencies and percentages, were compared using the chi-square test or Fisher's exact test when appropriate. A logistic regression model was used to determine the predictive ability of the continuous variables for identifying myocardial viability. Correlations for reproducibility analysis were performed using the Pearson correlation coefficient. As an alternative to the logistic model, receiver operating characteristic (ROC) curves were also computed for prediction of myocardial viability among the different measurements.

\section{Results}

The contemplated populace were characterized by the outcomes into two gatherings: reasonable gathering (38 patients) and non feasible gathering ( 12 patients) notwithstanding the benchmark group (25 patients) .

There was non factual huge distinction between the three gatherings with respect to

gauge attributes (Age and sex), clinical assessment (Blood pressure, Heart rate), hazard factors (Hypertension, DM, Dyslipidemia, Smoking), Door to expand time and end diastolic volume.

In any case, there was measurable huge contrast between the three gatherings with respect to time to entryway, End systolic volume, Ejection part, top systolic strain and strain rate (both at benchmark and following a half year)

Table (1) Comparison between the studied groups according to baseline characteristics.

\begin{tabular}{|c|c|c|c|c|}
\hline & \multicolumn{2}{|c|}{ STEMI $(n=50)$} & \multirow{2}{*}{ Control $(n=25)$} & \multirow{2}{*}{$\mathbf{P}$} \\
\hline & Viable $(n=38)$ & Non-viable $(n=12)$ & & \\
\hline Age (years) & & & & \\
\hline $\begin{array}{l}\text { Min. - Max. } \\
\text { Mean } \pm \text { SD. } \\
\text { SBP }\end{array}$ & $\begin{array}{c}40-67 \\
51.63 \pm 8.58\end{array}$ & $\begin{array}{c}41-63 \\
51.67 \pm 8.35\end{array}$ & $\begin{array}{c}40-65 \\
52.32 \pm 6.63\end{array}$ & 0.941 \\
\hline $\begin{array}{l}\text { Min. - Max. } \\
\text { Mean } \pm \text { SD. } \\
\text { DBP }\end{array}$ & $\begin{array}{c}110-160 \\
132.6 \pm 12.23\end{array}$ & $\begin{array}{c}100-190 \\
145 \pm 31.19\end{array}$ & $\begin{array}{c}110-160 \\
133.6 \pm 12.21\end{array}$ & 0.077 \\
\hline $\begin{array}{l}\text { Min. - Max. } \\
\text { Mean } \pm \text { SD. } \\
\text { HR }\end{array}$ & $\begin{array}{c}70-100 \\
83.68 \pm 6.75\end{array}$ & $\begin{array}{c}60-120 \\
90 \pm 20.89\end{array}$ & $\begin{array}{c}70-90 \\
82.8 \pm 6.78\end{array}$ & 0.120 \\
\hline
\end{tabular}




\begin{tabular}{lcccc}
\hline Table (1) Continue & & & \\
\hline Min. - Max. & $70-104$ & $60-110$ & $70-94$ & 0.108 \\
Mean \pm SD. & $87.58 \pm 8.2$ & $84.33 \pm 17.29$ & $82.24 \pm 6.96$ & \\
HTN & & $10(83.3)$ & $13(52)$ & 0.139 \\
n $(\%)$ & $20(52.6)$ & $8(66.7)$ & $10(40)$ & 0.096 \\
DM & & $2(16.7)$ & $11(44)$ & 0.089 \\
$\begin{array}{l}\text { DLP } \\
\text { n (\%) }\end{array}$ & $12(31.6)$ & $8(66.7)$ & $11(44)$ & 0.367 \\
$\begin{array}{l}\text { Smoking } \\
\text { n(\%) }\end{array}$ & $8(21.1)$ & & & \\
\hline
\end{tabular}

Table (2) Comparison between the studied groups according to the time interval.

\begin{tabular}{|c|c|c|c|c|}
\hline & \multicolumn{2}{|c|}{ STEMI $(n=50)$} & \multirow{2}{*}{$\mathbf{t}$} & \multirow{2}{*}{$\mathbf{P}$} \\
\hline & Viable $(n=38)$ & Non-viable $(n=12)$ & & \\
\hline \multicolumn{5}{|l|}{ Symptom to door } \\
\hline Min. - Max. & $30-300$ & $140-330$ & \multirow{2}{*}{$2.110 *$} & \multirow{2}{*}{$0.040^{*}$} \\
\hline $\begin{array}{l}\text { Mean } \pm \text { SD. } \\
\text { Door to balloon }\end{array}$ & $167.4 \pm 61.85$ & $210.0 \pm 58.15$ & & \\
\hline Min. - Max. & $30-60$ & $30-60$ & \multirow[b]{2}{*}{1.124} & \multirow[b]{2}{*}{0.267} \\
\hline Mean \pm SD. & $42.37 \pm 11.55$ & $46.67 \pm 11.55$ & & \\
\hline
\end{tabular}

Table (3) Comparison between the studied groups according to echocardiographic findings.

\begin{tabular}{|c|c|c|c|c|c|}
\hline \multirow{2}{*}{$\begin{array}{l}\text { Echocardiographic } \\
\text { findings }\end{array}$} & \multicolumn{2}{|c|}{ STEMI (n=50) } & \multirow{2}{*}{$\begin{array}{l}\text { Control } \\
(n=25)\end{array}$} & \multirow{2}{*}{$\mathbf{F}$} & \multirow{2}{*}{$\mathbf{P}$} \\
\hline & Viable $(n=38)$ & Non-viable $(n=12)$ & & & \\
\hline \multicolumn{6}{|l|}{ End diastolic volume } \\
\hline Min. - Max. & $81.6-201$ & $100.5-134.4$ & $89.8-155.9$ & \multirow{2}{*}{0.341} & \multirow{2}{*}{0.712} \\
\hline $\begin{array}{l}\text { Mean } \pm \text { SD. } \\
\text { End systolic volume }\end{array}$ & $123.8 \pm 29.65$ & $117.7 \pm 12.93$ & $120.6 \pm 17.57$ & & \\
\hline Min. - Max. & $32.5-79$ & $46.6-77.5$ & $26.9-63.1$ & \multirow{3}{*}{10.853} & \multirow{3}{*}{$<0.001 *$} \\
\hline Mean \pm SD. & $52.48 \pm 11.69$ & $63.08 \pm 11.81$ & $45.8 \pm 7.95$ & & \\
\hline Ejection fraction & & & & & \\
\hline Min. - Max. & $45-65$ & $34-64$ & $52-70$ & \multirow{2}{*}{21.398} & \multirow{2}{*}{$<0.001 *$} \\
\hline Mean \pm SD. & $55.47 \pm 6.83$ & $45.83 \pm 10.76$ & $61.8 \pm 4.65$ & & \\
\hline
\end{tabular}

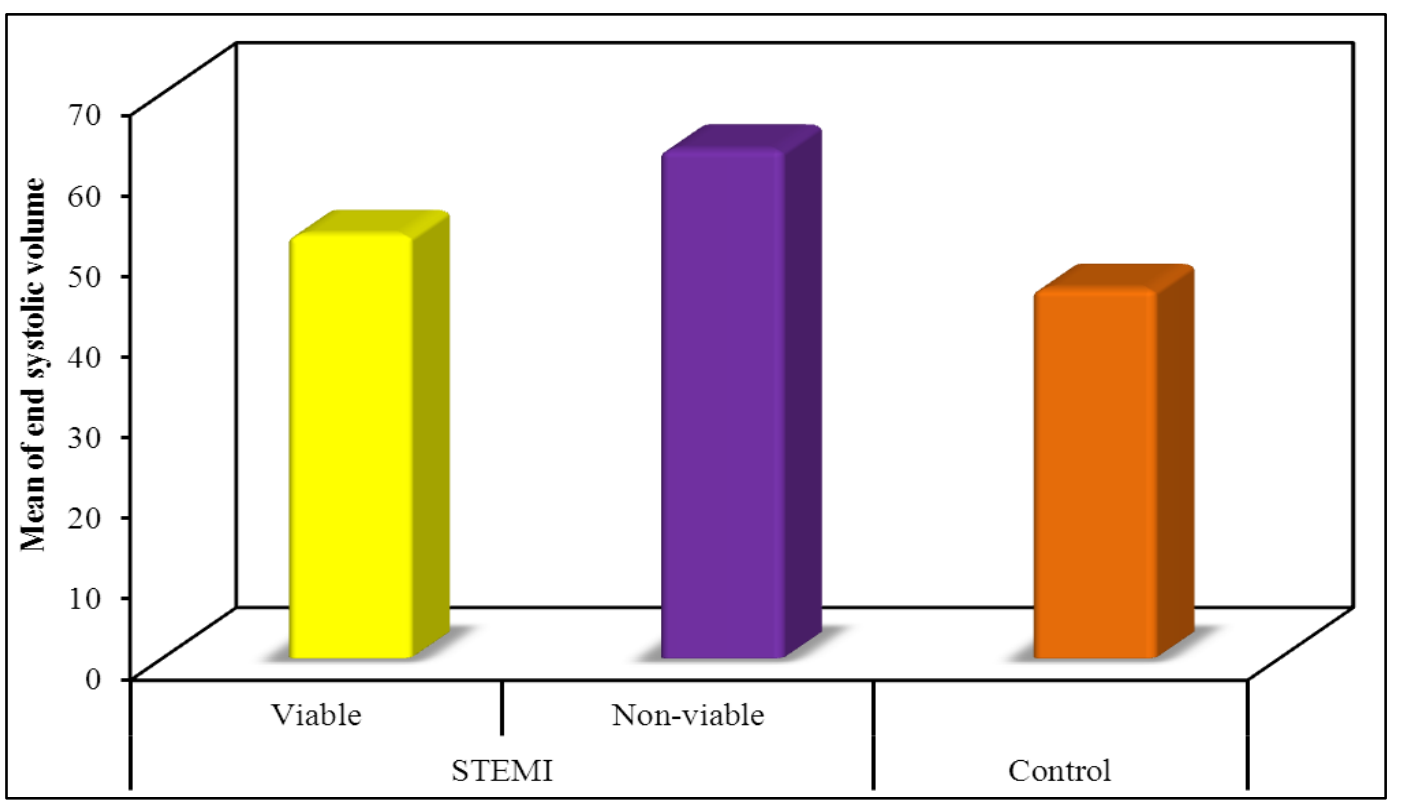

Fig (1) Comparison between the studied groups according to End systolic volume 


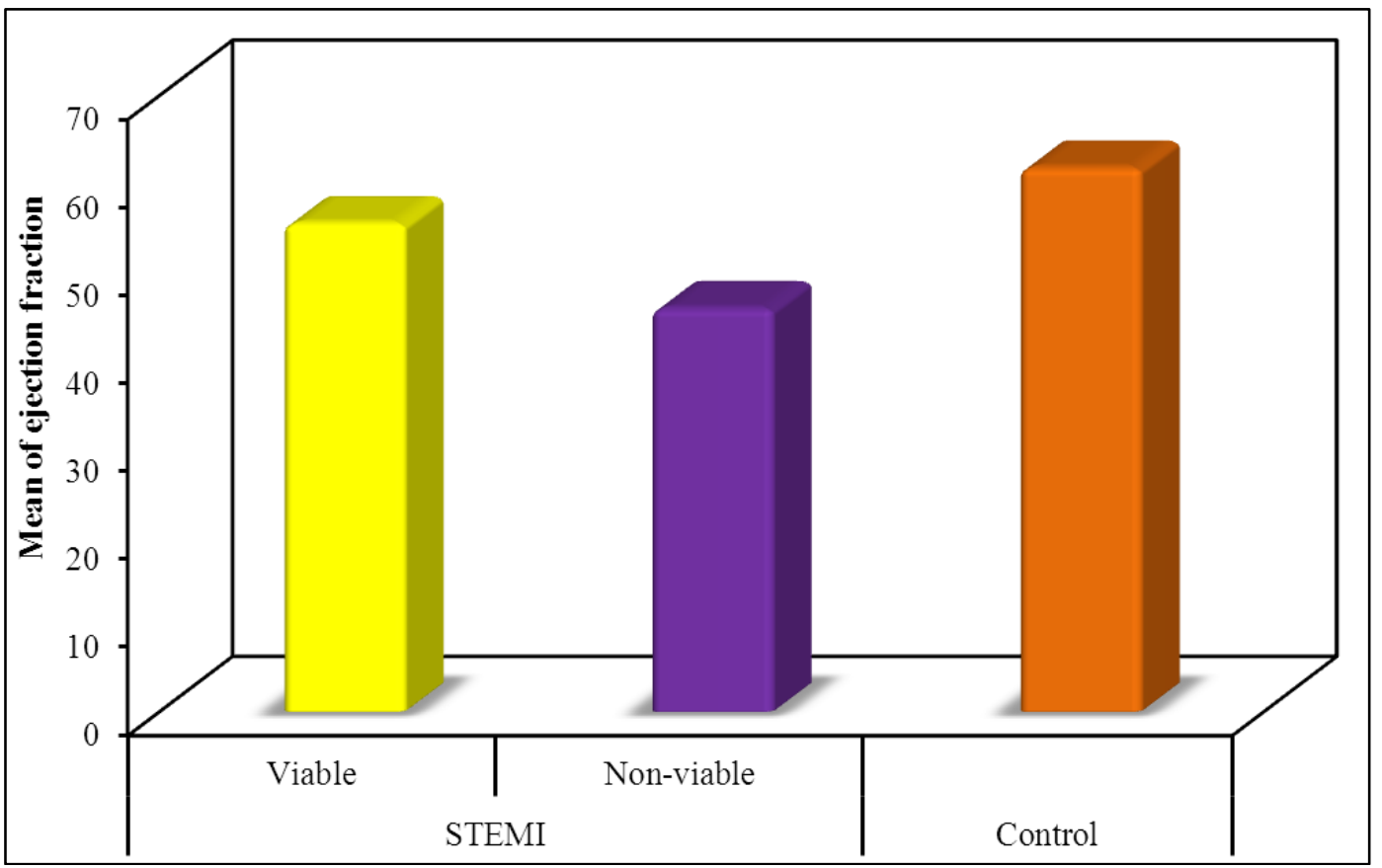

Fig (2)Comparison between the studied groups according to Ejection fraction.

\subsection{Angiographic findings}

\section{A- Infarction related artery}

In the studied group, LAD was the infarction related artery in all patients.

In the control group, LAD was free of stenosis or less than $30 \%$ in all patients.

B- Associated lesions:
In the studied group, there was a significant lesions in LCX in 2 patients in the viable group and in 3 patients in the non viable group, while RCA was significant in 4 patients in viable and 4 in non viable groups.

There were no significant lesions in LCX or RCA in the control group.

Table (4) Comparison between the studied groups according to angiographic findings and associated lesion.

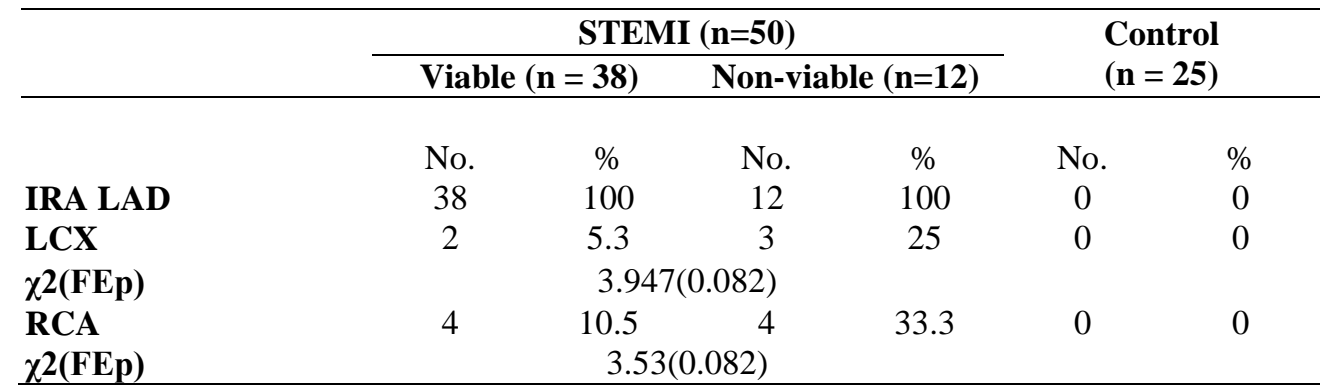

\subsection{D-speckle tracking}

7 segments of LAD territory were studied by $2 \mathrm{D}$ speckle tracking in all 50 patients in the studied group and 25 patients in the control group, then the segments were divided into viable and non viable according to result of Dobutamine Echo done after 6 months from myocardial infarction.

Baseline Peak longitudinal systolic strain ranged from $(-21--14)$ in the viable group with a mean $(-13.03 \pm 4.32)$, while in the non viable group, it ranged from $(-9--2)$ with a mean $(-5.32 \pm 2.31)$.

In the control group, it ranged from (-34 -14) with a mean $(-23.10 \pm 3.96)$.
Baseline Peak longitudinal systolic strain rate ranged from $(-2--0.7)$ in the viable group with a mean $(-0.94 \pm 0.23)$, while in the non viable group, it ranged from $(-1-0)$ with a mean $(-0.51 \pm 0.29)$.

In the control group, it ranged from (-2 - $1.2)$ with a mean $(-1.38 \pm 0.51)$.

\section{After 6 months}

Peak longitudinal systolic strain ranged from $(-34--13)$ in the viable group with a mean $(-17.35 \pm 5.99)$, while in the non viable group, it ranged from $(-10--3)$ with a mean $(-6.81 \pm 1.99)$. 
Peak longitudinal systolic strain rate ranged group, it ranged from $(-1-0)$ with a mean ($0.55 \pm 0.28)$. from $(-2--0.6)$ in the viable group with a mean $(-1.06 \pm 0.3)$, while in the non viable

Table (5) Comparison between the studied groups according to strain and strain rate.

\begin{tabular}{|c|c|c|c|c|c|c|}
\hline & & \multicolumn{2}{|c|}{ STEMI $(\mathbf{n}=\mathbf{3 5 0})$} & \multirow{2}{*}{$\begin{array}{l}\text { Control } \\
(n=175)\end{array}$} & \multirow{2}{*}{ Test of sig. } & \multirow{2}{*}{$\mathbf{P}$} \\
\hline & & Viable $(n=288)$ & Non-viable $(n=62)$ & & & \\
\hline \multirow[t]{2}{*}{ Strain } & $\begin{array}{c}\text { Baseline } \\
\text { Min. }- \text { Max. } \\
\text { Mean } \pm \text { SD. } \\
\text { After } 6 \text { months }\end{array}$ & $\begin{array}{c}-21--14 \\
-13.03 \pm 4.32\end{array}$ & $\begin{array}{c}-9--2 \\
-5.32 \pm 2.31\end{array}$ & $\begin{array}{c}-34--14 \\
-23.1 \pm 3.96\end{array}$ & $\mathrm{H}=376.231 *$ & $<0.001 *$ \\
\hline & $\begin{array}{l}\text { Min. - Max } \\
\text { Mean } \pm \text { SD } \\
\text { Baseline }\end{array}$ & $\begin{array}{c}-34--13 \\
-17.35 \pm 5.99\end{array}$ & $\begin{array}{c}-10--3 \\
-6.81 \pm 1.99\end{array}$ & --- & $\mathrm{H}=252.676^{*}$ & $<0.001 *$ \\
\hline \multirow[t]{2}{*}{$\begin{array}{l}\text { Strain } \\
\text { rate }\end{array}$} & $\begin{array}{l}\text { Min. - Max. } \\
\text { Mean } \pm \text { SD. } \\
\text { After } 6 \text { months }\end{array}$ & $\begin{array}{c}-2--0.07 \\
-0.94 \pm 0.23\end{array}$ & $\begin{array}{c}-1-0 \\
-0.51 \pm 0.29\end{array}$ & $\begin{array}{c}-2-1.2 \\
-1.38 \pm 0.51\end{array}$ & $\mathrm{H}=235.215^{*}$ & $<0.001 *$ \\
\hline & $\begin{array}{l}\text { Min. - Max. } \\
\text { Mean } \pm \text { SD }\end{array}$ & $\begin{array}{c}-2--0.6 \\
-1.06 \pm 0.3 \\
\end{array}$ & $\begin{array}{c}-1-0 \\
-0.55 \pm 0.28\end{array}$ & $\begin{array}{l}--- \\
--- \\
\end{array}$ & $\mathrm{H}=205.976^{*}$ & $<0.001 *$ \\
\hline
\end{tabular}

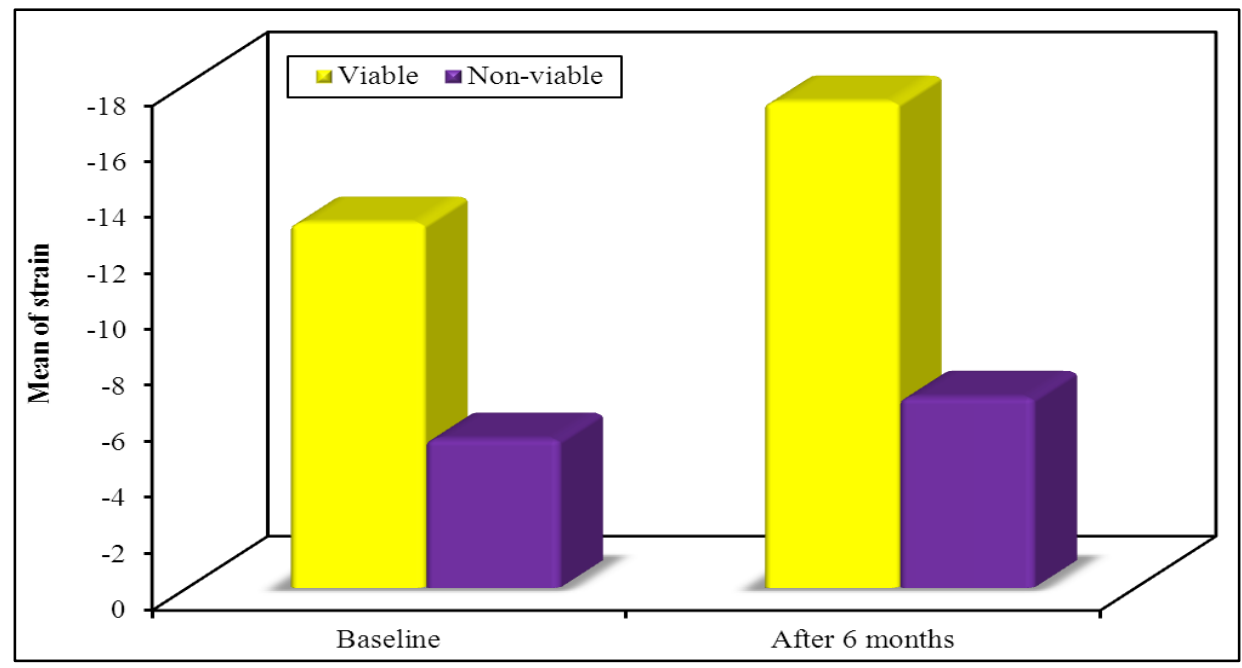

Fig (3) Comparison between the studied groups according to strain.

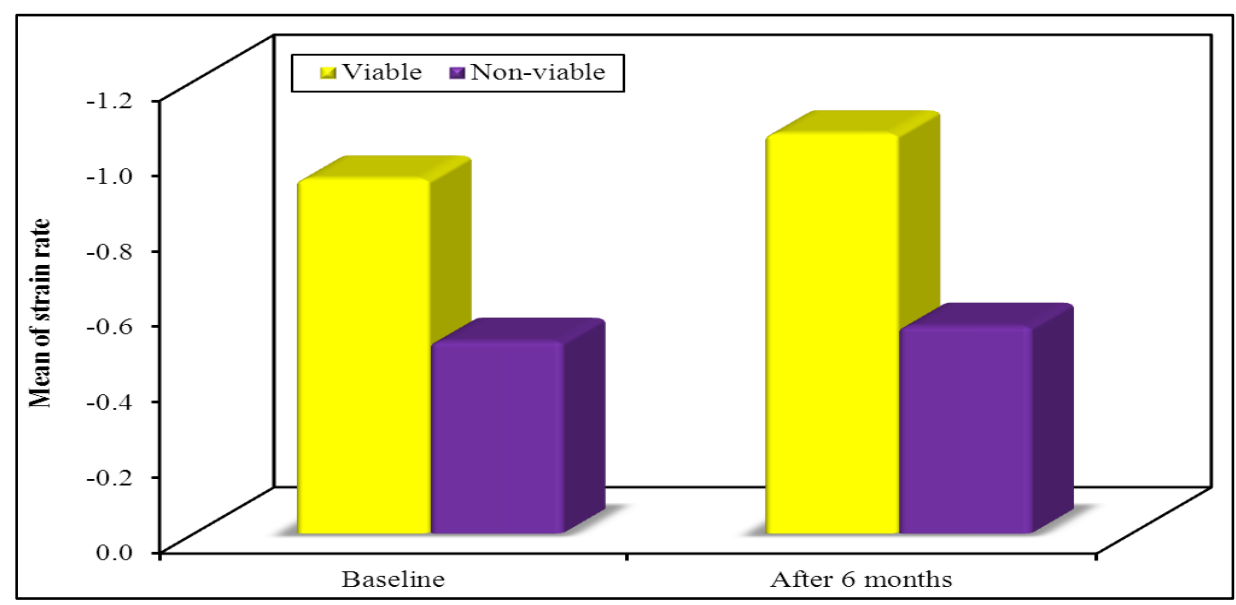

Fig (4)Comparison between the studied groups according to strain rate.

\section{Prediction of viable segments:}


ROC curve done for baseline peak systolic strain and strain rate and revealed that:

AUC for peak systolic strain (0.957, p. $<0.001)$, 95\%C.I. $(0.937-0.976)$ showed that a cut off level of <-9 had sensitivity of 86.11 and specificity 87.1 for prediction of viable myocardium.
AUC for peak systolic strain rate $(0.87, \mathrm{p}$. $<0.001)$, 95\%C.I. $(0.809-0.931)$ showed that a cut off level of <-0.7 had sensitivity of 91.6 and specificity 74.19 for prediction of viable myocardium.

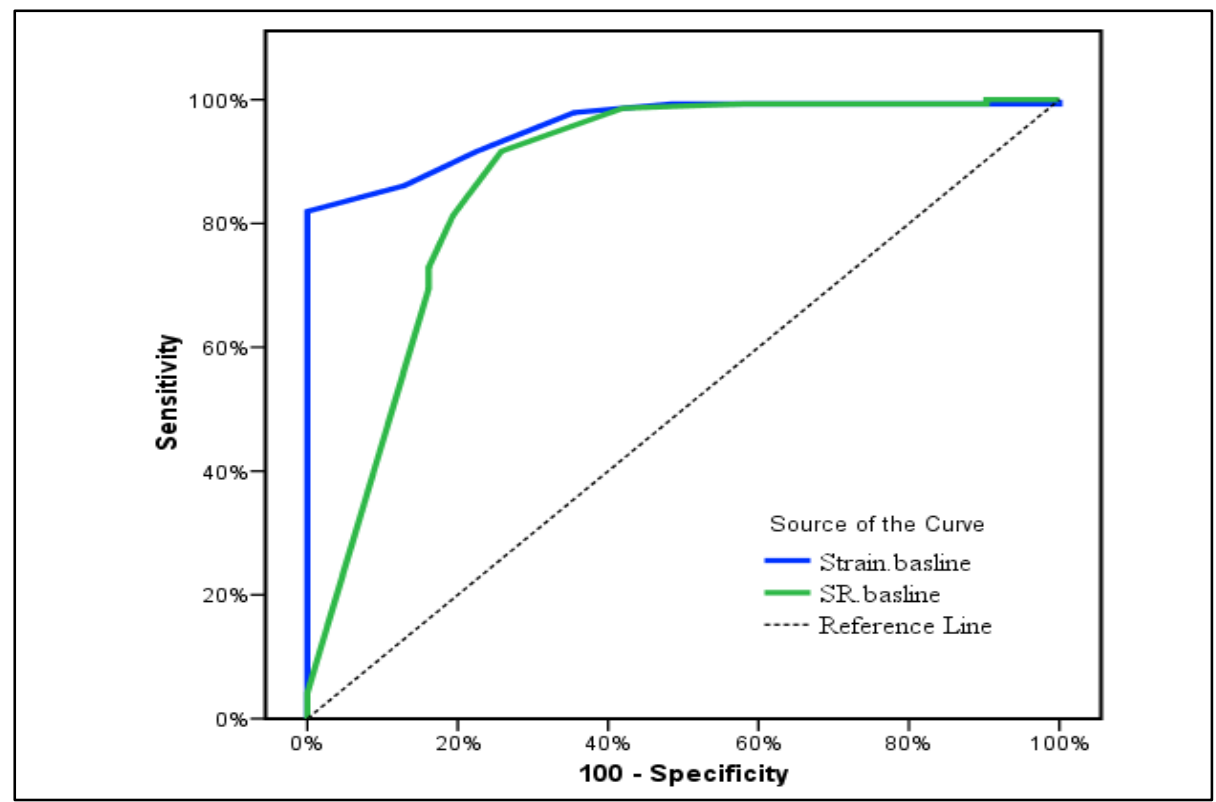

Fig (5)ROC curve for Strain and Strain rate to predict viable vs non-viable.

Table (6) Agreement (sensitivity, specificity) for Strain and Strain rate to predict viable vs non-viable.

\begin{tabular}{lcccccccc}
\hline Baseline & AUC & P & 95\% C.I & Cut off & Sensitivity & Specificity & PPV & NPV \\
\hline Strain & 0.957 & $<0.001 *$ & $0.937-0.976$ & $\leq-9$ & 86.11 & 87.10 & 96.9 & 57.4 \\
Strain rate & 0.870 & $<0.001 *$ & $0.809-0.931$ & $\leq-0.7$ & 91.67 & 74.19 & 94.3 & 65.7 \\
\hline
\end{tabular}

\section{Discussion}

Evaluating practicality in patients with AMI is significant for deciding patient anticipation and choosing whether revascularization is suitable. A few modalities, for example, 2-D echocardiography, differentiate improved MRI, 64-cut CT, and F18-FDG PET - can be utilized to evaluate myocardial reasonability. The affectability and explicitness of these modalities are comparable [6].

In any case, the difference improved MRI and F18-FDG PET are costly and not accessible to patients with intense conditions, for example, AMI. The 64-cut CT has the radiation risk even this methodology has been broadly performed as of late.

Evaluating myocardial practicality dependent on WMSI during dobutamine echocardiography is troublesome and abstract. In this manner, progressively achievable, reasonable, quantitative, and quick techniques to evaluate myocardial practicality are required, particularly in patients with AMI.
Tissue Doppler imaging permits the nonintrusive estimation of myocardial strain in the LV. Estimating strain and strain rate utilizing low-portion dobutamine echocardiography was possible, and their utilization in blend with surveying WMS improves the affectability of reasonability evaluations made utilizing dobutamine echocardiography[7].

Doppler-inferred PSS spoke to a clinical technique for distinguishing effectively contracting and subsequently reasonable myocardium in hound models. Likewise, the LS proportion determined utilizing Doppler echocardiography recognized zones of dynamic withdrawal and corruption in hound models of intense coronary occlusion [8].

Also, a past report found an opposite connection between the segmental strain and the transmural degree of localized necrosis in each fragment, as decided utilizing contrastimproved MRI after coronary reperfusion. Investigating sections utilizing the pinnacle systolic strain rate, as determined from computerized strain rate imaging examination 
from the dobutamine stress echocardiography reaction, offers prognostic data that is autonomous from and steady to standard WMSI. Nonetheless, tissue Doppler imaging is restricted by edge reliance. The subsequent strain rate profiles additionally will in general be uproarious, and estimations can be troublesome. The 2D-STI defeats these impediments. It is a novel technique for evaluating movement dependent on tissue following utilizing time-area preparing, and quantifies strain free of both heart interpretation and point dependency [9].

Along these lines, this examination was directed on 50 patients introduced by first time Acute Myocardial Infarction and rewarded by Primary PCI, at that point echocardiography wad accomplished for all patients with $2 \mathrm{D}$ dot following for early forecast of myocardial practicality, at long last pressure Dobutamine reverberation completed a half year after for assessment of myocardial feasibility as a highest quality level, and the myocardial portions were partitioned into suitable and non reasonable.

As to of this investigation, there was no noteworthy measurable contrast between both examined gathering and control bunch in regards to general qualities and hazard factors, But there was huge factual distinction among suitable and non feasible gatherings in regards to indication to entryway time, discharge part and end systolic volume, these outcomes come in concurrence with Jong Shin Woo et.al, who directed an examination in 2015 to foresee myocardial feasibility ahead of schedule after myocardial dead tissue by two-dimensional dot following imaging.

Additionally estimations of local pinnacle longitudinal strain and strain rate were higher in vaiable gathering in contrast with non practical gathering both at benchmark (- 13.03 $\pm 4.32,-5.32 \pm 2.31)$ and After a half year ($17.35 \pm 5.99,-6.81 \pm 1.99)$ individually with huge factual distinction $(\mathrm{p}<0.001)$.

Additionally estimations of local pinnacle longitudinal strain rate were higher in vaiable gathering in contrast with non practical gathering both at benchmark (- $0.94 \pm 0.23$, $0.51 \pm 0.29)$ and After a half year $(-1.06 \pm$ $0.30,-0.55 \pm 0.28)$ individually with huge factual distinction $(\mathrm{p}<0.001)$.

Our outcomes come in concurrence with Shokr., et al. who directed an investigation in 2016 to decide the general exactness of Tissue Doppler imaging (TDI)- based and STE-based estimations of myocardial strain and strain rate for the discovery of myocardial reasonability before revascularization utilizing SPECT imaging as a best quality level, and went to the outcome that lower strain and strain rate esteems exist very still utilizing STE in the non-feasible portions contrasted with the suitable gatherings of the comparing an area and an expansion of strain and strain rate esteems in light of LDD was recognized in the practical gathering however not in the nonfeasible ones, and they found a slice off highlight foresee myo 7 cardial suitability utilizing the ROC bend, at > $-4.5 \%$ pinnacle longitudinal systolic strain by STE at LDD picked as a cut-off point, with an affectability of $87.24 \%$ and a particularity of $84.10 \%$.(10)

$\mathrm{Be}$ that as it may, in this investigation, the cutoff highlight foresee myocardial suitability was $>-9 \%$ top longitudinal systolic strain by STE inside 3 days of myocardial localized necrosis with affectability 86.1 and explicitness 87.1

The conceivable clarification of the contrast between both cut off levels might be because of that our estimations were done inside 3 days of myocardial dead tissue, )for example after revascularization( and that the patients remembered for shokr et al, study were known to have interminable ischemic coronary illness with left ventricular systolic brokenness however the patients remembered for this investigation had intense myocardial dead tissue just because. additionally, they utilized SPECT imaging as a highest quality level rather than pressure dobutamine reverberation.

Similarly, Martin et al., in 2013. compared the speckle tracking echocardiography derived systolic longitudinal strain with rest single photon emission computed tomography perfusion imaging and to define the optimal cut-offs for peak longitudinal systolic strain to discriminate transmural scar on contrastenhanced magnetic resonance imaging (ceCMR). Correlation was found between regional peak longitudinal systolic strain and DE on ceCMR. The peak longitudinal systolic strain optimal cutoff $-5.3 \%$ identified segments with delayed enhancement $>75 \%$ on ceCMR (sensitivity $83.1 \%$, specificity $84.6 \%$ ). STE enabled identification of LV non-viable segments. In comparison with rest myocardial SPECT perfusion imaging, STE is more accurate in predicting non-viable myocardium, and this was compatible to our findings [11].

Likewise, the cut off worth was lower conceivably because of the distinction in the examined gatherings. the patients remembered for martin et al. study had ischemic cardiomyopathy and LV launch frac $\neg$ tion $<40 \%$ and rejected patients who expe $\neg$ rienced myocardial dead tissue during the most recent a half year preceding confirmation and Patients 
with intense coronary conditions or any indications of intense myocardial ischemia, however in this examination, we included patients with first time intense myocardial localized necrosis.

Loïc Bière et al., 2014. were surveyed the estimation of STE performed right on time after a first ST-section rise myocardial dead tissue so as to foresee infarct size and utilitarian recuperation at 3-month development. Longitudinal strain $>-6.0 \%$ inside the infarcted territory showed $96 \%$ particularity and $61 \%$ affectability for foreseeing the constancy of akinesia at 3month development. Dot following strain imaging performed right on time after a STEMI is anything but difficult to-use as a marker for tireless akinetic regions at 3 months. also, this was practically identical to our discoveries, yet with a lower cut off worth and helpless affectability.

The distinction could on the grounds that they rely upon Late gadolinium-improved heart attractive imaging as a gold criticized for myocardial viability[12].

Also,Cimino S., et al. in 2012 tried whether GLS and RLS could likewise recognize early myocardial brokenness and transmural degree of myocardial scar in patients with intense ST height myocardial localized necrosis (STEMI) and generally saved

LV work, RLS was fundamentally lower in DE-fragments when contrasted and ordinary myocardium $(\mathrm{P}, 0.0001)$. A cutoff estimation of RLS of $-12.3 \%$ by (ROC) bends recognized DE-portions (affectability 82\%, particularity $78 \%$ ), though a cut-off estimation of $-11.5 \%$ distinguished transmural degree of DE (affectability 75\%, explicitness 78\%) [13].

The higher cut off an incentive in Cimino S., et al., study could be as they rejected patients whose LV discharge portion $<40 \%$.

Likewise, Chan et al., in 2006 found that feasible myocardium demonstrated higher strain rates than scarred tissue after dobutamine mixture. They detailed that expansion of strain and strain rate with dobutamine is a marker of myocardial feasibility, which was good with our findings [14].

Jong Shin Woo et.al, led an examination in 2015 to anticipate myocardial feasibility right on time after myocardial dead tissue by twodimensional spot following imaging and announced that 2D-STI is attainable for evaluating myocardial reasonability, and the pinnacle systolic strain rate may be the most dependable indicator of myocardial practicality in patients with AMI. ROC bends uncovered that underlying SSR had the best capacity to evaluate segmental myocardial feasibility. Utilizing a cutoff of 0.72 , beginning SSR had an affectability of $88 \%$ and particularity of $69 \%$ for recognizing feasible from non-suitable segments [15].

These outcomes accompanied concurrence with our outcomes with comparable cut off estimation of pinnacle systolic strain rate $\leq-0.7$ with affectability 91.67 and explicitness 74.19.

\section{Conclusion \& Recommendation}

In patients with ongoing first intense MI, Strain and strain rate estimations are attainable, economical, quantitative, and fast strategies that can foresee myocardial practicality with high affectability and particularity.

\section{References}

[1] P.T. O'Gara, F.G. Kushner, D.D. Ascheim, ACCF/AHA guideline for the management of ST-elevation myocardial infarction: a report of the American College of Cardiology Foundation / American Heart Association Task Force on Practice Guidelines. Circulation , Vol.127 (4), PP.e362 - e425,2013

[2] T. Vartdal, H. Brunvand, E. Pettersen, Early prediction of infarct size by strain doppler echocardiography after coronary reperfusion. J Am Coll Cardiol, Vol. 49,PP. 1715-1721,2007.

[3] M. Al Moudiet, Z.H. Sun, Diagnostic value of (18)F-FDG PET in the assessment of myocardial viability in coronary artery disease: A comparative study with (99m)Tc SPECT and echocardiography. J Geriatr Cardiol ,Vol.11, PP.229-236,2014.

[4] M. Habis, A. Capderou, S. Ghostine, Acute myocardial infarction early viability assessment by 64-slice computed tomography immediately after coronary angiography: comparison with low-dose dobutamine echocardiography. J Am CollCardiol ,Vol. 49, PP. 1178$1185,2007$.

[5] B. Amundsen, T. Helle-Valle, T. Edvardsen, Non-invasive myocardial strain measurement by speckle tracking echocardiography. J Am CollCardiol , Vol. 47, PP. 789-793,2006.

[6] E. Altiok, S. Tiemann, M. Becker, Myocardial deformation imaging by twodimensional speckle-tracking echocardiography for prediction of global and segmental functional changes after acute myocardial infarction: a comparison with late gadolinium enhancement cardiac magnetic resonance. $\mathrm{J}$ Am Soc 
Echocardiogr , Vol. 27, PP. 249$257,2014$.

[7] L. Hanekom, C. Jenkins, L. Jeffries, Incremental value of strain rate analysis as an adjunct to wall-motion scoring for assessment of myocardial viability by dobutamine echocardiography: A followup study after revascularization. Circulation , Vol. 11, PP. 38923900,2005.

[8] E. Lyseggen, H. Skulstad, T. Helle-Valle, Myocardial strain analysis in acute coronary occlusion: A tool to assess myocardial viability and reperfusion. Circulation, Vol.112, PP.3901-3910,2005.

[9] T. Vartdal, H. Brunvand, E. Pettersen, Early prediction of infarct size by strain doppler echocardiography after coronary reperfusion. J Am Coll Cardiol ,Vol. 49,PP.1715-1721,2007.

[10] D.Shokr, M. Aly, A. Abd Elrahman, Myocardial Viability Assessment by Dobutamine Echocardiography using Tissue Doppler and Speckle-Tracking: Comparison with SPECT. ARC Journal of Cardiology ,Vol. 2, PP. 1-12,2016

[11] H. Martin, S. Tomas, K. Milan, Speckle tracking echocardiography derived systolic longitudinal strain is better than rest single photon emission tomography perfusion imagingfor nonviable myocardium identification. Biomed Pap Med Fac Univ, Vol. 157, PP.12-21,2013.

[12] B. Loïc, D. Erwan, T. Gwenola, Longitudinal Strain Is a Marker of Microvascular Obstruction and Infarct Size in Patients with Acute ST-Segment Elevation Myocardial Infarction. J Eur PMC, Vol.10, PP.1371,2014.

[13] S. Cimino , E .Canali, V. Petronilli, Global and regional longitudinal strain assessed by two-dimensional speckle tracking echocardiography identifies early myocardial dysfunction and transmural extent of myocardial scar in patients with acute ST elevation myocardial infarction and relatively preserved LV function. European Heart Journal - Cardiovascular Imaging , Vol.14,PP. 805-811,2013.

[14] J. Chan, L. Hanekom, C .Wong, Differentiation of subendocardial and transmural myocardial infarction using two-dimensional strain rate imaging to assess short and long axis function. J Am Coll Cardiol ,Vol.48, PP.2026-2033,2006.

[15] W.O.O. Jong Shin, Y.U. Tae-Kyung, Early prediction of myocardial viability after acute myocardial infarction by twodimensional speckle tracking imaging. Journal of Geriatric Cardiology ,Vol. 12,PP. 474-481,2015. 